\title{
Design and Impedance Modeling of a Compact Sequentially Rotated Quasi-Lumped Antenna Array for Wi-Fi Applications
}

\author{
Yazeed M. I. Qasaymeh \\ Department of Electrical Engineering, College of Engineering, Majmaah University, Al-Majmaah 11952, Saudi Arabia \\ Correspondence should be addressed to Yazeed M. I. Qasaymeh; yazed100@gmail.com
}

Received 29 June 2021; Revised 28 August 2021; Accepted 1 September 2021; Published 18 September 2021

Academic Editor: Mohammad Alibakhshikenari

Copyright (C) 2021 Yazeed M. I. Qasaymeh. This is an open access article distributed under the Creative Commons Attribution License, which permits unrestricted use, distribution, and reproduction in any medium, provided the original work is properly cited.

In this study, a miniaturized $2 \times 2$ sequentially rotated (SR), circularly polarized (CP), and quasi-lumped antenna array that resonates in the IEEE 802.11a band is introduced. The shorting pins technique is implemented to achieve circular radiation patterns, and the resonating elements are excited using a SR quarter-wavelength feeding network. A resonance model of the four radiating elements array is postulated to give a physical insight into the relative dimensions and to allow for a study of the resonance characteristics and the effect of the shorting pins. An antenna model is simulated, fabricated, and measured to authenticate this arrangement, giving results of $|\mathrm{S} 11|<-10 \mathrm{~dB}$ and axial ratio $(\mathrm{AR})<3 \mathrm{~dB}$ for bandwidths of $3.85 \%$ $(5.645-5.867 \mathrm{GHz})$ and $1.54 \%(5.77-5.86 \mathrm{GHz})$ for right-hand circular polarization (RHCP). The size of the antenna array structure is $0.696 \lambda_{0} \times 0.599 \lambda_{0} \times 0.0157 \lambda_{0}$ at a center frequency of $5.8 \mathrm{GHz}$.

\section{Introduction}

Shortly after their introduction in the 1970s, microstrip patch antennas attracted considerable attention due to their useful features, such as ease of analysis and fabrication, desirable radiation characteristics, low mass, cost efficiency, straightforward integration, minimal profile, mechanical robustness, and compatibility with MIMC designs $[1,2]$. However, they were considered to be impractical for mobile communications, particularly, for installation in mobile handsets because of their large size. Thus, printed microwave quasi-lumped antennas appeared to be the most suitable contenders to replace classical patch antennas, as they were not subject to size limitations $[3,4]$.

Single-element antennas are normally low-gain devices that need to be arrayed to achieve high gain performance. Several types of feed have been used in linear arrays to meet this requirement, including series [5] and parallel microstrip feeds [6]. In general, a series feed topology results in a more concise network that involves shorter transmission lengths, fewer junctions, and lower insertion losses compared to a parallel feed; however, it is subject to a narrow bandwidth and phase differences due to the differences in line lengths [7]. In contrast, a parallelfed topology gives a wider bandwidth, as it does not produce high mismatch losses [8]. In addition, corporate and parallel feeds have the advantage that the excitation for such arrays has good design elasticity and ease of integration when two-dimensional arrays are created. The feed magnitude for each element can be easily controlled by employing either amplifiers or attenuators, and the phase can be controlled using phase shifters.

Numerous single-feed CP microstrip antenna methods have been documented in the literature, such as a U-slot microstrip antenna [9], an equilateral triangular single-feed circularly polarized microstrip antenna [10], a CP annularring microstrip antenna developed using a pair of inserted slits [11], and a square-ring microstrip antenna with a truncated corner design [12]. Other designs have been based on the carving of a split ring resonator on a patch [13], etching of asymmetrical slots into a single probe-feed square microstrip [14], the use of an L-shaped microstrip connected to a tag-chip and terminated by a shorting pin coupled to a microstrip antenna [15], and the use of a circular eccentric 
ring to generate $\mathrm{CP}$ radiation [16]. The aforementioned methods aimed to achieve CP by altering the physical dimensions of the antenna.

In this paper, a quasi-lumped resonator antenna array is presented with the aim of achieving size reduction and circular radiation performance. In conventional approaches, if the single element is small, the array is also small. In view of this, a corporate feed design for a quasi-lumped array antenna network will be implemented to reduce the footprint of the array configuration.

The three major objectives of this study are (i) to provide an array equivalent impedance circuit used to give a frequency resonance preliminary indication, (ii) to generate $\mathrm{CP}$ radiation, and (iii) to design a miniaturized array structure with the smallest possible size. The antenna array equivalent circuit is built based on array feed and elements' dimensions. $\mathrm{CP}$ is achieved using the technique of loading of shorting pins, while a quarter-wavelength transformer technique is used to feed the antenna array to improve the gain and reduce the overall array size.

In Section 2, the proposed antenna array excitation technique and feeding method are introduced. The impedance resonance model of the array is described in Section 3. A discussion and the experimental results from the proposed array are presented in Section 4.

\section{Configuration of the Antenna Array}

2.1. Quasi-Lumped Geometry. The components required for the approximate microwave operation of lumped elements in microstrip structures are microstrip shorts and stubs with dimensions shorter than a quarter wavelength at the resonating frequency. These are referred to as quasi-lumped. A primary benefit of this method is the simplicity of transition into an equivalent circuit, wherein capacitors and inductors constitute a microstrip structure. Figure 1 shows the structure of a single quasi-lumped element resonator. The equivalent lumped elements of the single proposed antenna are shown in Figure 2. A winding-line inductor can be used to increase the capacitance. The inductor $L$ is molded as a finger that is connected across the capacitor $C$. The pad capacitors $C_{P 1}$ and $C_{P 2}$ connected to both sides of the structure act as capacitors to the ground and can be adjusted in order to tune the resonant frequency of the proposed resonator. The details of the process of calculating the operating frequency of the proposed single quasi-lumped antenna and its dimensions are discussed in [17]. Table 1 presents the dimensions of a single quasi-lumped element at a resonant frequency of $5.8 \mathrm{GHz}$.

2.2. Shorting Pins. The use of shorting pins was first introduced in [18] to achieve $\mathrm{CP}$ radiation. If the shorting pins are situated near to the edges of a diagonal-fed patch, two resonant modes are excited, one of which is higher than the other, and hence, CP is achieved [19]. The polarization of microstrip antennas can be tuned by adjusting the positions of the shorting posts (pins) within the boundaries of the antenna. Inserting the shorting posts into the antenna patch changes the smallest point of minor frequency to a higher frequency, yielding a wide axial ratio band. Other techniques for slicing slots or adding tails are less beneficial in terms of size mitigation compared to the use of shorting pins, which is the most effective solution for the size miniaturization of patch antennas. The impact of the shorting pins depends on several parameters, such as the number and radii of the posts and the thickness of the microstrip antenna. The shorting pins are directly connected between the radiating element and the ground plane.

\subsection{Feeding Topology. Single feeds for $C P$ radiation opera-} tion can be categorized into two types: single port/single feed and single port/double feed. The single-port feed technique is easy to construct [20]. SR arrays were first proposed in [21] to improve the performance of $C P$ arrays. Microstrip antenna arrays use $S R$ to achieve improvements in polarization purity, impedance matching, and pattern symmetry across wider bandwidths $[22,23]$.

In general, corporate feed networks are used to provide power splits of two-element numbers. The quarter-wavelength approach is a technique that is used to match the transmission line to the antenna using a transformer. The impedance characteristics of the transmission line are restricted in terms of the range and values; thus, the quarterwavelength transformer technique is most suitable when microstrip transmission lines are used [24, 25].

The proposed design is shown in Figure 3. Our array consists of four radiating quasi-lumped elements fed by a $2 \times 2 S R$ microstrip in the front layer and a ground plane in the bottom layer. The shorting pins are located at the center of the resonating elements. A quarter-wave impedance transformer of $70.7 \Omega$ is used to convert a $100 \Omega$ for each radiating element fed by a $50 \Omega$ line, thus creating the conditions for impedance matching.

\section{Array Equivalent Impedance Model}

In this study, an equivalent impedance model is proposed in order to give a physical description of the resonance frequency of the array. This model is used to validate the simulated and measured resonance operations. The antenna array consists of a quarter-wavelength microstrip feed and resonating elements. The quarter-wave microstrip feed is developed by cascading three segments with characteristic impedance values of 50, 70.7, and $100 \Omega$, as shown in Figure 3. The microstrip circuit consists of the equivalent radiation conductance $G_{r m}$ and the susceptance of the fringing field capacitance of the microstrip $C_{L}$. The conductance $G_{r m}$ and capacitance are calculated using ( 1 and (2), respectively, as reported in [26]:

$$
G_{r m}=\frac{160 \pi^{2} h^{2}}{Z_{c m}^{2} \lambda_{0}^{2} \varepsilon_{c m}}
$$

where $h$ is substrate height, $Z_{c m}$ is characteristic impedance of the microstrip, and $\varepsilon_{c m}$ is effective dielectric constant.

$$
C_{l}=\frac{l_{\mathrm{eq}} \mathrm{C} \sqrt{\varepsilon_{c m}}}{Z_{c m}}
$$




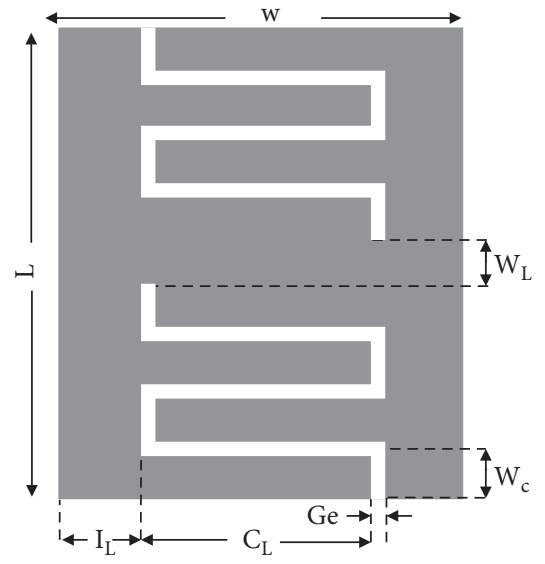

(a)

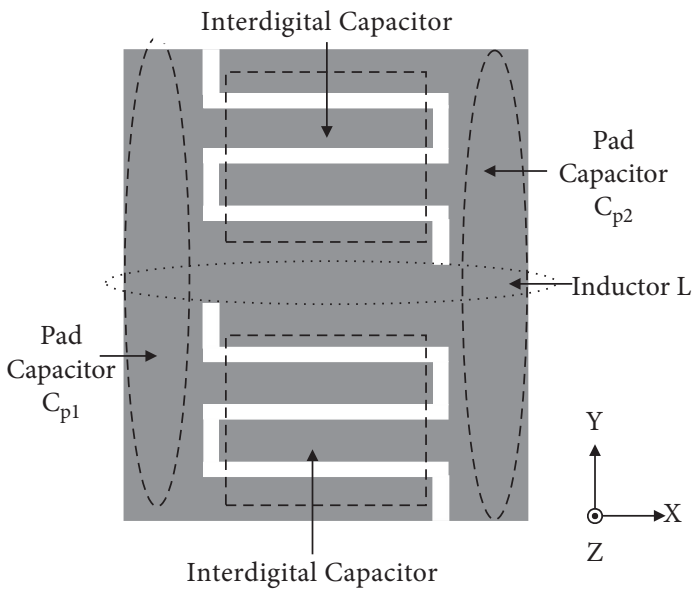

(b)

Figure 1: Proposed quasi-lumped antenna: (a) dimensions used to calculate the lumped elements; (b) allocation of the lumped elements.

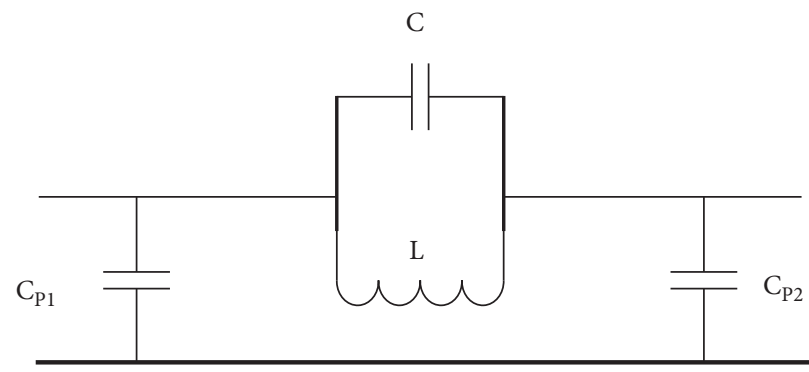

FIgURE 2: Equivalent circuit for the proposed antenna.

where $l_{\mathrm{eq}}$ is equivalent extralength of microstrip and $C$ is velocity of light.

The quasi-lumped equivalent lumped elements $C, L$, $C P 1$, and $C P 2$ are derived from equations (3-5), respectively. Table 2 presents the equivalent lumped elements for a single quasi-lumped element at $5.8 \mathrm{GHz}$ obtained using the equations reported in [27-29]:

$$
\begin{aligned}
C= & \varepsilon_{0}\left(\frac{\varepsilon_{r}+1}{2}\right)\left[(N-\Delta) C_{L}\right], \\
L= & 200 \times 10^{-9} I_{L}\left[\ln \left(\frac{2 I_{L}}{W_{L}+h}\right)+0.50049+\frac{W_{L}}{3 I_{L}}\right] \\
C_{P}= & {\left[\frac{2.85 \varepsilon_{\text {eff }}}{\ln \left[1+(1 / 2)\left(8 h / \varepsilon_{\text {eff }}\right)\left[\left(8 h / \varepsilon_{\text {eff }}\right)+\sqrt{\left(8 h / \varepsilon_{\text {eff }}\right)^{2}+\pi^{2}}\right]\right]}\right] } \\
& \times \frac{1}{25.4 \times 10^{-3}},
\end{aligned}
$$

where $h$ is substrate thickness, $I_{L}$ is inductor length, $w_{L}$ is inductor width, $N$ is the number of fingers, and $\Delta$ is the correction factor between 0.44 and 0.65 for $N=1$ and 2, respectively.
The equivalent circuit for the shorting posts is represented in the form of shunt inductances in the locations at which the posts are connected to the ground. The inductive reactance of the posts and the feed probe are calculated from

$$
X_{L}=\frac{377}{\sqrt{\varepsilon_{r}}} \tan \left(\frac{2 \pi h}{\lambda_{0}}\right) .
$$

Figures 4(a) and 4(b) show the equivalent circuits for a single quasi-lumped array element with a shorting post and with a single segment microstrip feed, respectively. The impedance of the microstrip feeder segments and the four radiating elements are connected to form the array equivalent resonant circuit, which is used to study the resonance behavior of the array.

\section{Results and Discussion}

Figure 5 shows the equivalent input impedance, modeled using Agilent Advanced Design System (ADS). The resistance and capacitance values representing the microstrip segment feeder and the four resonating quasi-lumped elements are given in Tables 2 and 3. The impedance model is used to predict the resonance behavior of the antenna array before modeling and fabrication. No radiation pattern is expected from this model. 
TABle 1: Parameters for the elements of the proposed quasi-lumped antenna.

\begin{tabular}{lr}
\hline Parameter & Dimensions (mm) \\
\hline$W_{e}$ & 0.35 \\
$\mathrm{I}_{\mathrm{L}}$ & 3.35 \\
$C$ & 3.05 \\
$N$ & 8 \\
$I_{L} /$ & 1.23 \\
$g_{e}$ & 1.23 \\
$W_{L}$ & 1.2 \\
$L$ & 5.4 \\
$W$ & 5.8 \\
$h$ & 0813 \\
\hline
\end{tabular}

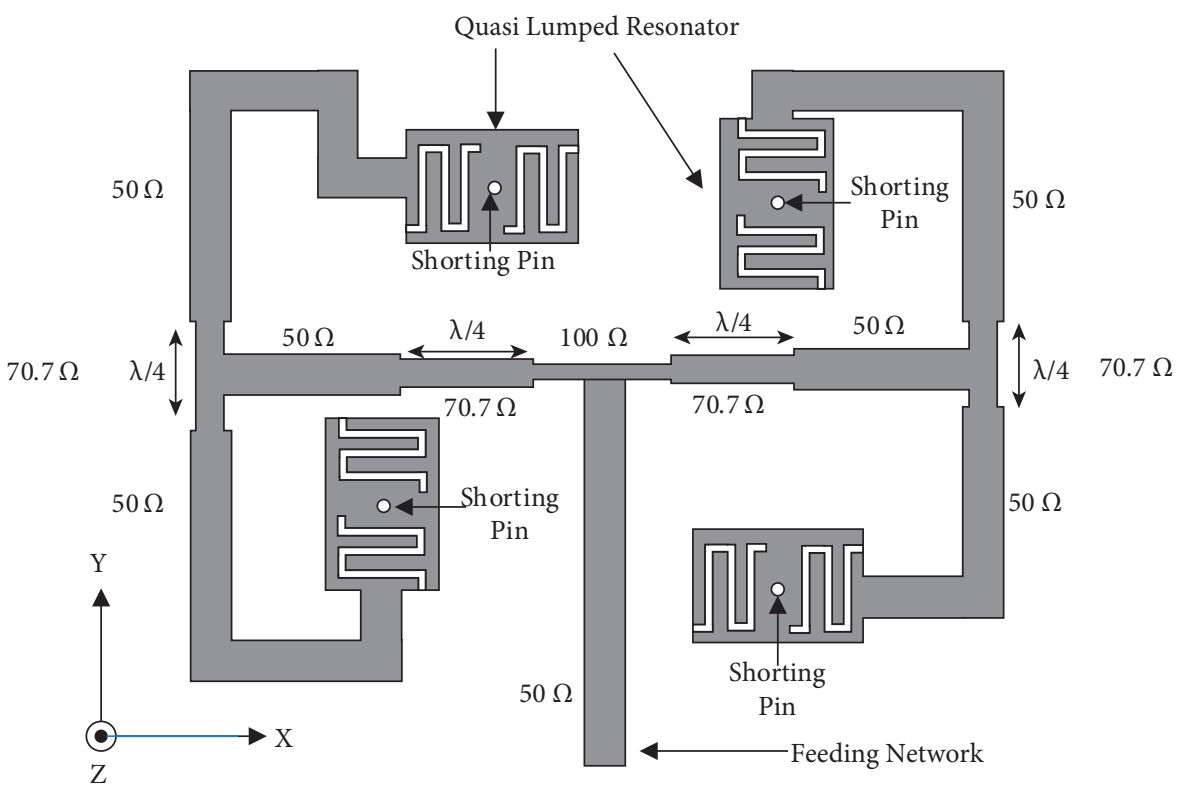

FIGURE 3: Proposed SR quarter-wavelength quasi-lumped antenna array.

TABLE 2: Equivalent lumped elements for the quasi-lumped resonator.

\begin{tabular}{lc}
\hline Value & Parameter \\
\hline$C$ & $0.347 \mathrm{PF}$ \\
$C_{P 1}$ & $0.17 \mathrm{PF}$ \\
$C_{P 2}$ & $0.17 \mathrm{PF}$ \\
$L$ & $1.47 \mathrm{nH}$ \\
\hline
\end{tabular}

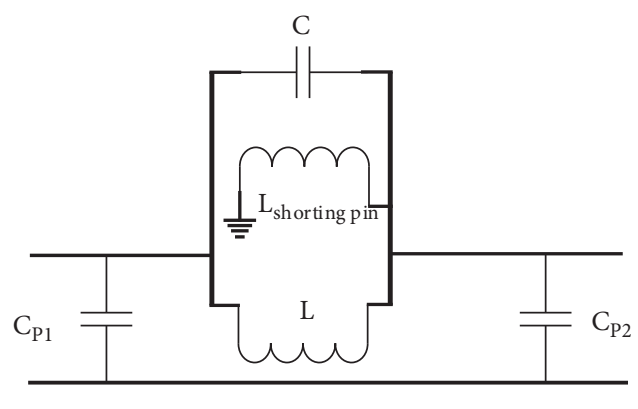

(a)

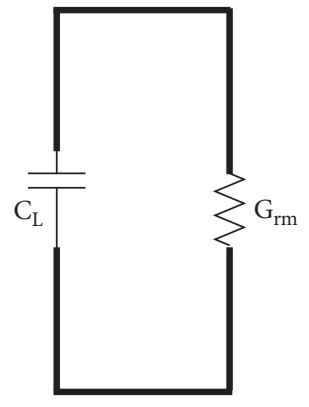

(b)

Figure 4: Equivalent circuits for (a) a single quasi-lumped element with a shorting pin at the center and (b) a microstrip feed. 


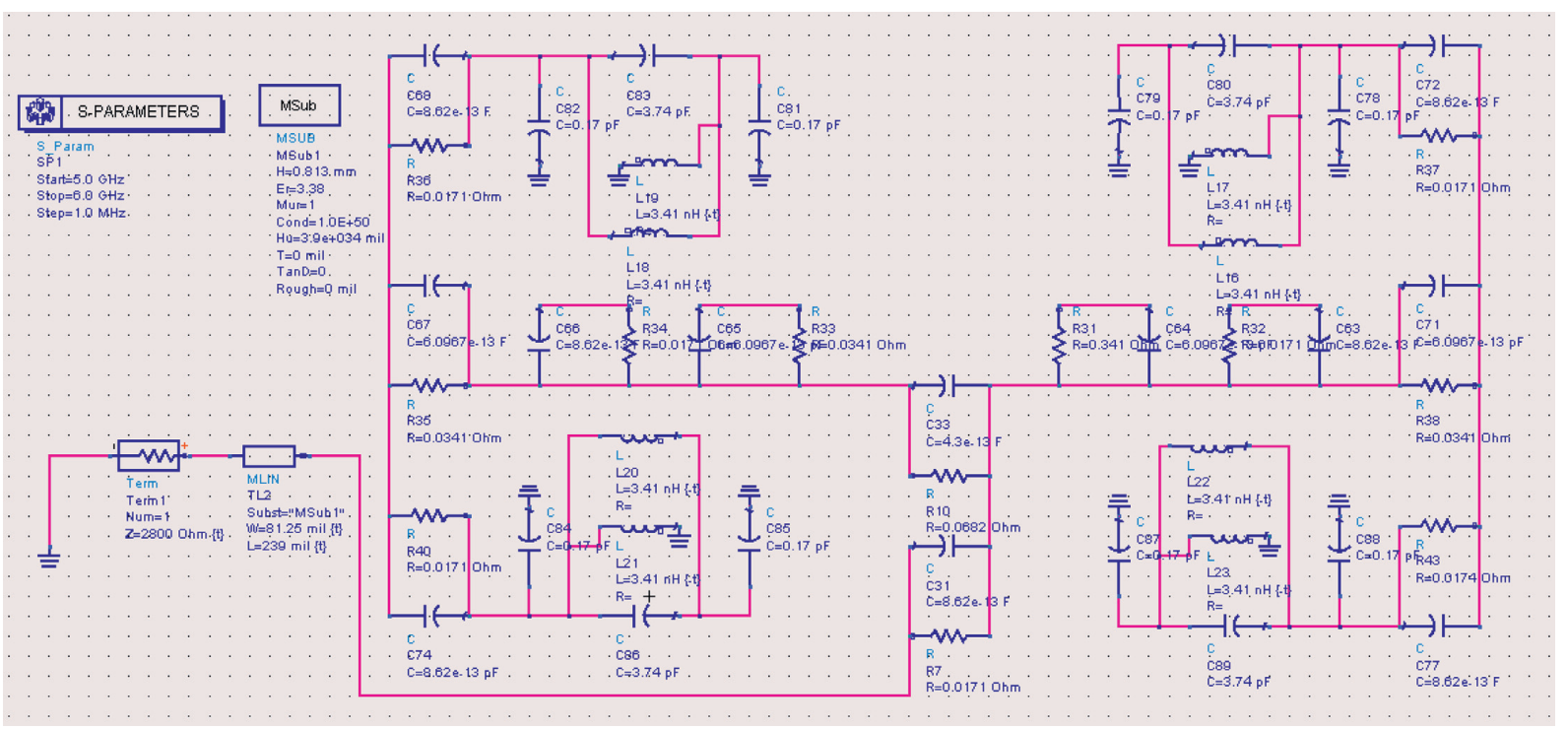

FIGURE 5: Equivalent impedance model for the antenna array, modeled in ADS.

TABLE 3: Equivalent lumped elements for the microstrip feeder segments.

\begin{tabular}{lcc}
\hline$G_{r m}(\Omega)$ & $C_{L}[F]$ & Characteristic impedance $(\Omega)$ \\
\hline 0.0682 & $4.3 \times 10^{-13}$ & 100 \\
0.0171 & $8.62 \times 10^{-13}$ & 50 \\
0.0341 & $6.0967 \times 10^{-13}$ & 70.7 \\
\hline
\end{tabular}

Figure 6 shows the fabricated quasi-lumped antenna array. The overall dimensions of the antenna array are $31 \times 36 \mathrm{~mm}^{2}$. A single-port array consists of $2 \times 2$ SR quasilumped elements in the top layer and a ground plane in the bottom layer. In the quarter-wave transformer method, an $S R$ is used to feed the single-element resonators on a RO4003 C microwave substrate with a relative permittivity of 3.38 and a thickness of $0.813 \mathrm{~mm}$. The width and length of the quarter-wavelength transformer are 1.036 and $7.03 \mathrm{~mm}$, respectively, and the $100 \Omega$ and $50 \Omega$ impedance widths are equal to $0.46 \mathrm{~mm}$ and $1.898 \mathrm{~mm}$, respectively. The resonating elements are spaced at half wavelengths, and the main purpose of the proposed antenna is to excite the elements and generate a circular radiation output, therefore implementing the shorting pins loading technique. The shorting pins are located at the center of the quasi-lumped element.

Figure 7 shows the power flow simulated by the CST software over the proposed antenna. The power flow from the feeding port over the quarter-wave feeding network to the radiating quasi-lumped elements reaches a maximum at $5.8 \mathrm{GHz}$, thus ensuring that the maximum power is radiated from the quasi-lumped radiators. The magnitude of the current density for an array element at $5.8 \mathrm{GHz}$ is depicted in Figure 8 , and it can be observed that the current distribution is concentrated within the quasi-lumped fingers.

Figure 9 shows the effect of changes in the shorting diameter on $S_{11}$ for a single resonance quasi-lumped element, simulated using CST Microwave Studio. It can be seen that the proposed resonator operates at $5.8 \mathrm{GHz}$ without the use of shorting pins. In addition, when the diameter is increased, the resonance shifts to a higher frequency. When the diameter of the shorting pin is $2 \mathrm{~mm}$, the optimum return loss is reached at $-24.94 \mathrm{~dB}$.

Figure 10 presents the simulated and measured results for the input return loss. The return loss calculated using ADS modeling occurs at $5.8 \mathrm{GHz}$, with a minimal value of $-20.81 \mathrm{~dB}$. Based on this result, we were able to validate the intended design before prototyping was carried out and measurements were taken. At this stage, various design parameters were not considered, such as the surrounding boundary of the antenna, soldering, and mismatches, and this can explain the slight difference between the modeled results and the simulated and measured ones. The simulated return loss exhibited a bandwidth of $201 \mathrm{MHz}$ in the range $5.66-5.861 \mathrm{GHz}$, with a minimal loss of $35.5 \mathrm{~dB}$ at $5.81 \mathrm{GHz}$. The measured return loss exhibited a bandwidth of $222 \mathrm{MHz}$ in the range $5.645-5.867 \mathrm{GHz}$, with a minimal loss of $35.68 \mathrm{~dB}$ at $5.814 \mathrm{GHz}$. We can therefore say that there is a good agreement between the simulated and measured results. The divergence in the results is primarily due to small construction errors and the nonuniformity arising from the manual soldering of the SMA connectors.

The simulated and measured E-co-polarization (RHCP) and E-cross-polarization (LHCP) patterns in the $x z$ plane at the design frequency of $5.8 \mathrm{GHz}$ are shown in Figure 11(b). Here, co-polarization (RHCP) is higher than cross polarization (LHCP) by $30 \mathrm{~dB}$ in the broadside direction. In general, the variance between the simulated and measured antenna patterns is within $20 \mathrm{~dB}$, and the measured patterns agree well with the simulated ones. Figures 11(a) and 11(c) 


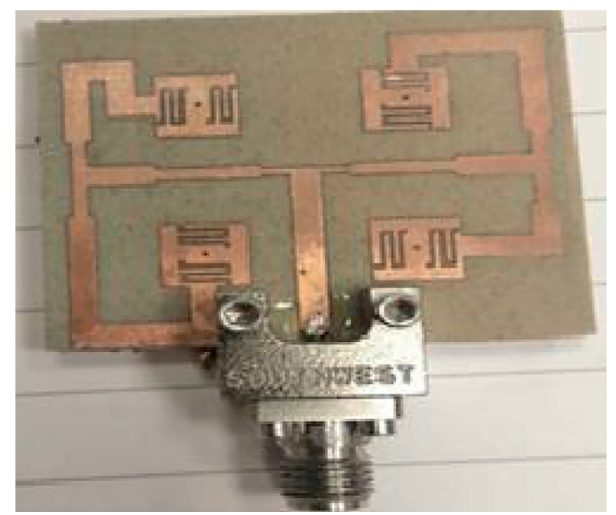

Figure 6: Photograph of the fabricated quasi-lumped antenna array.

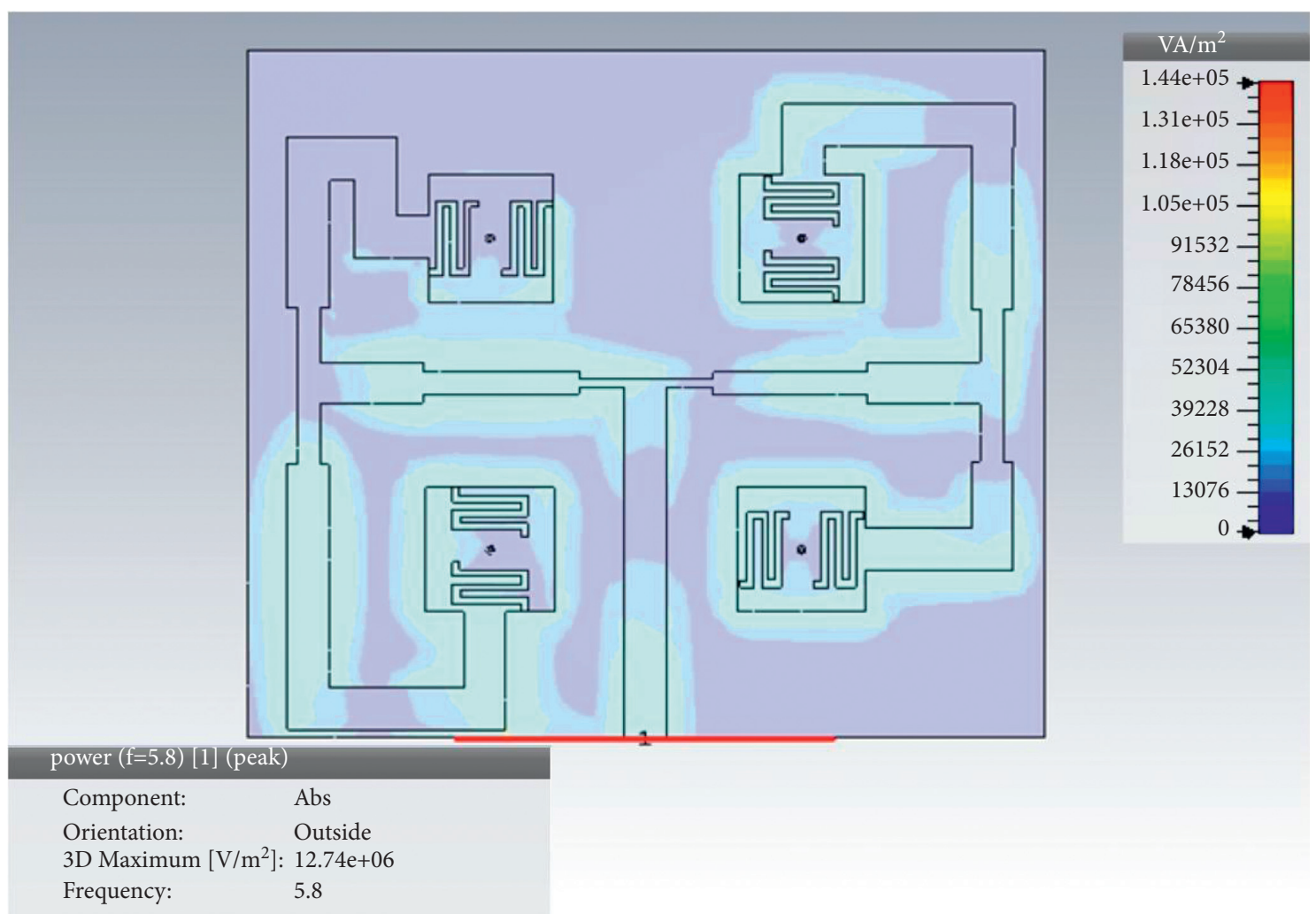

Figure 7: Power flow in the proposed quasi-lumped antenna array at $5.8 \mathrm{GHz}$.

show the radiation patterns at the minimum and maximum resonance frequencies.

Figure 12 shows the ARs for the proposed antenna, which are determined by measuring the fields in the vertical and horizontal planes. The simulated and measured $3 \mathrm{~dB}$ AR bandwidths for the proposed antenna are $5.79-5.86 \mathrm{GHz}$ and $5.77-5.86 \mathrm{GHz}$, respectively. The deviation between the simulated and measured results may be caused by several reasons such as the experiment accuracy, the experiment range, the loss tangent of the substrate, and the parasitic effects of the SMA connectors. However, the measured and simulated results show reasonable agreement.

Figure 13 shows the simulated and measured gains for the resonance bands. The maximum simulated gain is around $8 \mathrm{dBi}$ at $5.66 \mathrm{GHz}$, while the maximum measured gain is $7.48 \mathrm{dBi}$ at $5.66 \mathrm{GHz}$. This minor difference between the simulated and measured results can be attributed to fabrication tolerances and material losses. A reflector can be used in the bottom plane to enhance the gain performance. 


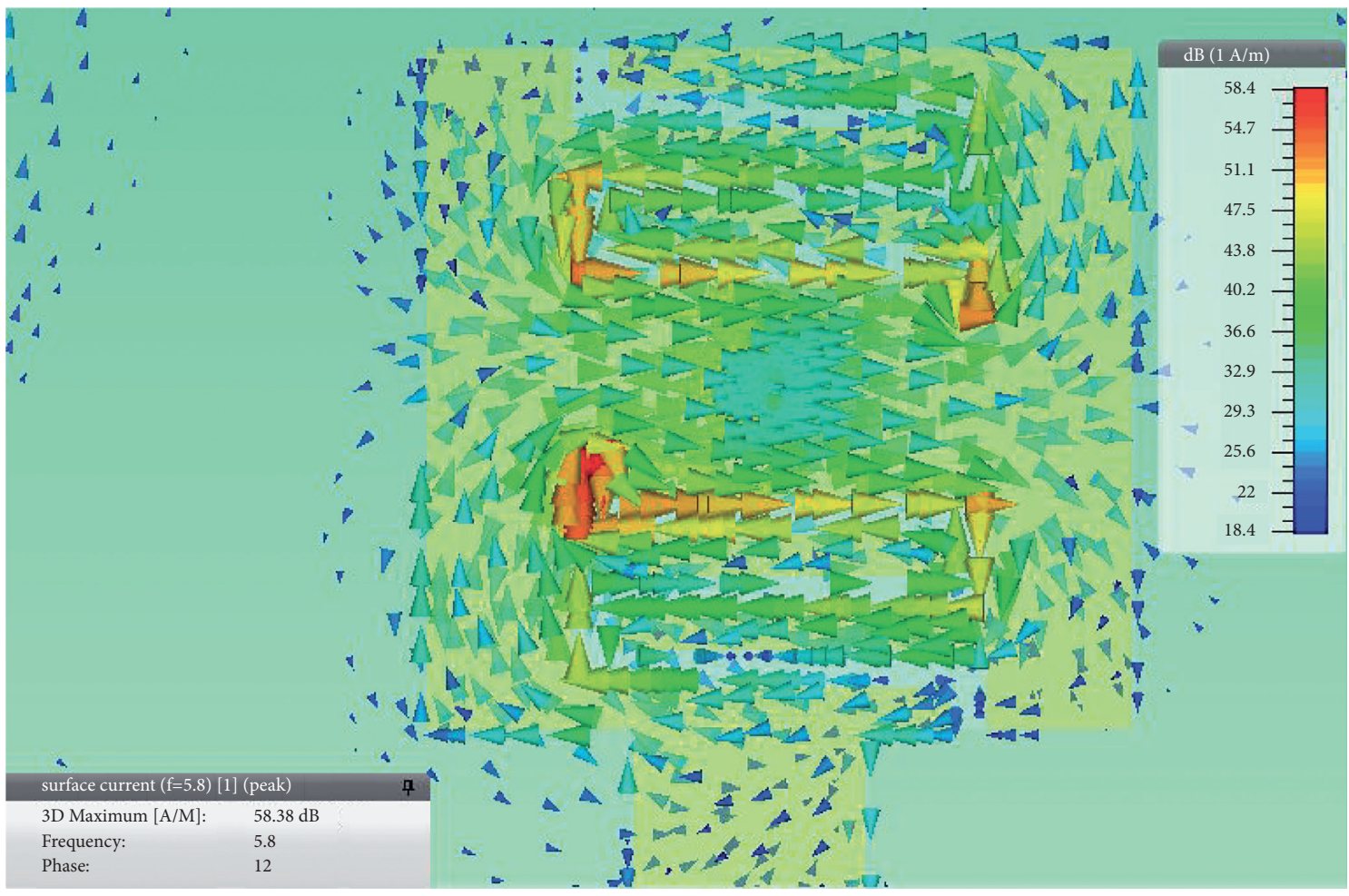

Figure 8: Surface current distribution for an array element at $5.8 \mathrm{GHz}$.
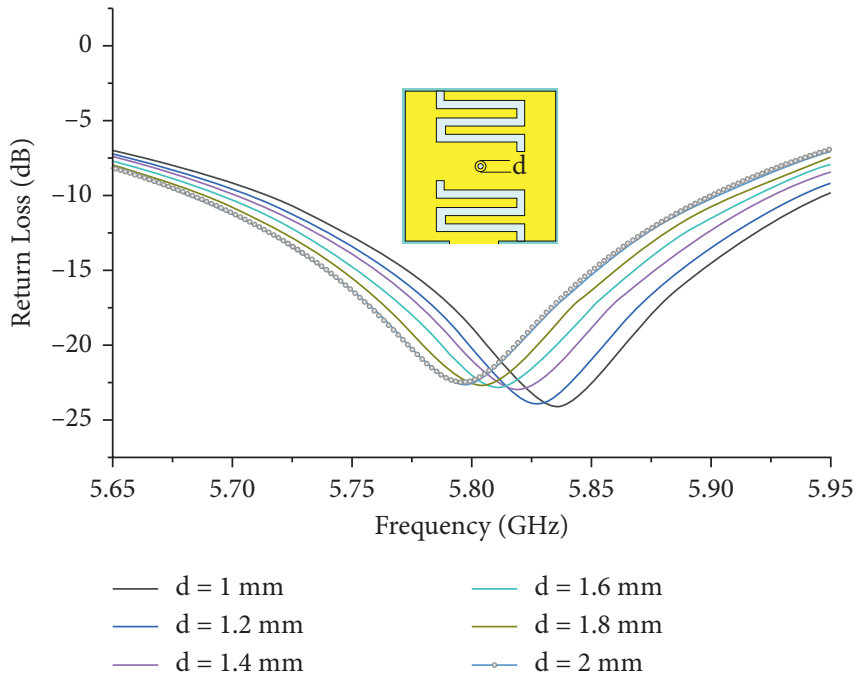

FIgURE 9: Effects of changes in the diameter of the shorting pin diameter on $S_{11}$.

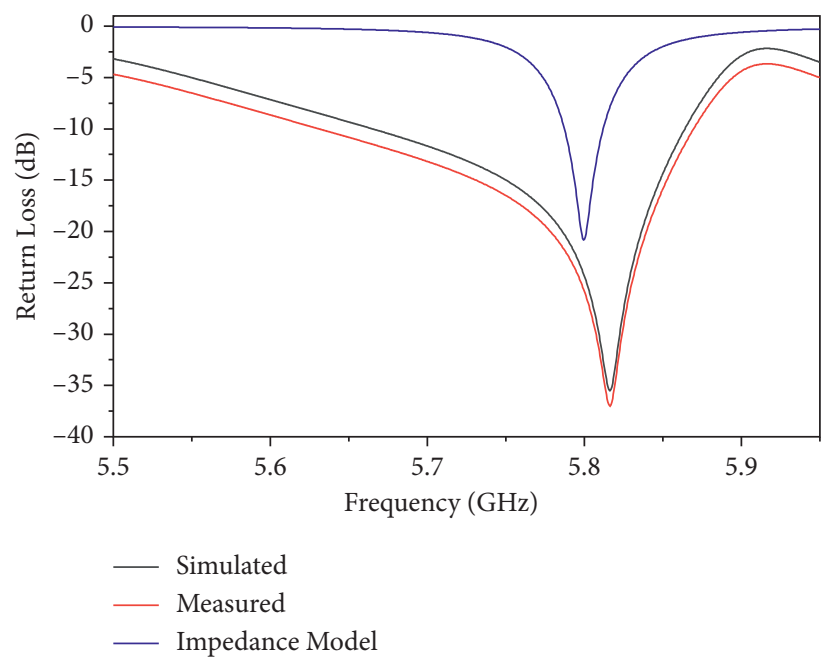

Figure 10: Simulated and measured reflection coefficients. 


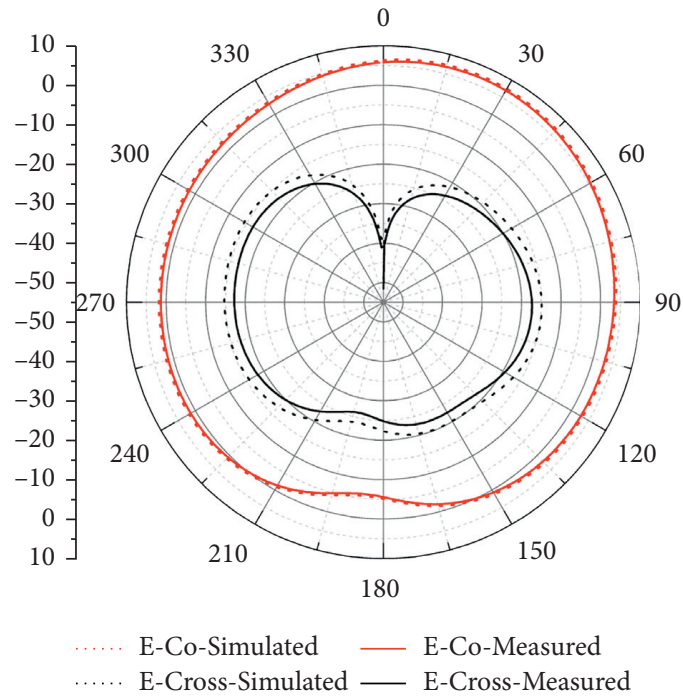

(a)

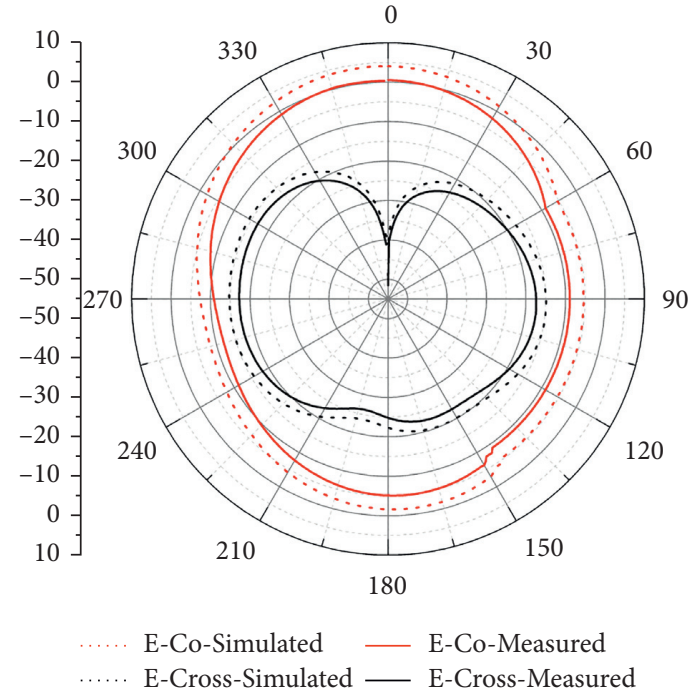

(b)

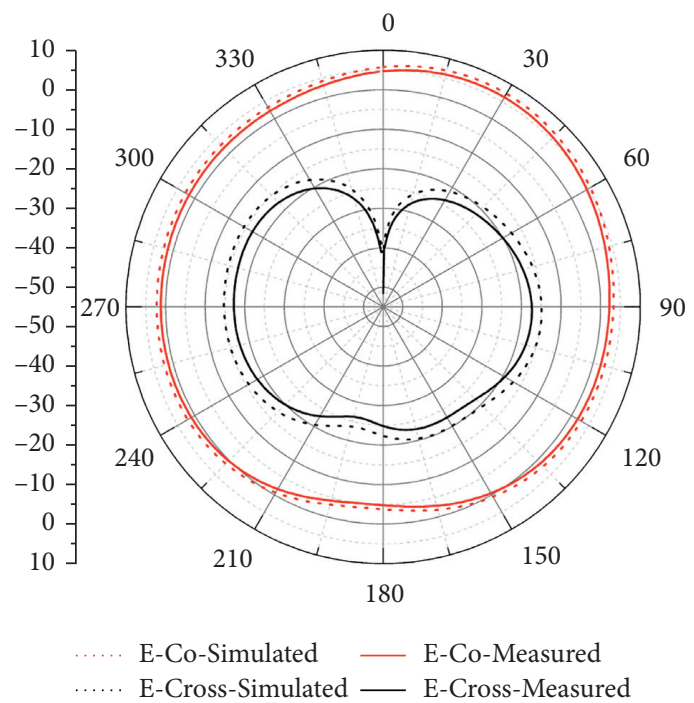

(c)

Figure 11: Simulated and measured E-co-polarized and E-cross-polarized patterns at the $x z$ plane: (a) at $5.7 \mathrm{GHz}$; (b) at $5.8 \mathrm{GHz}$; (c) at $5.85 \mathrm{GHz}$.

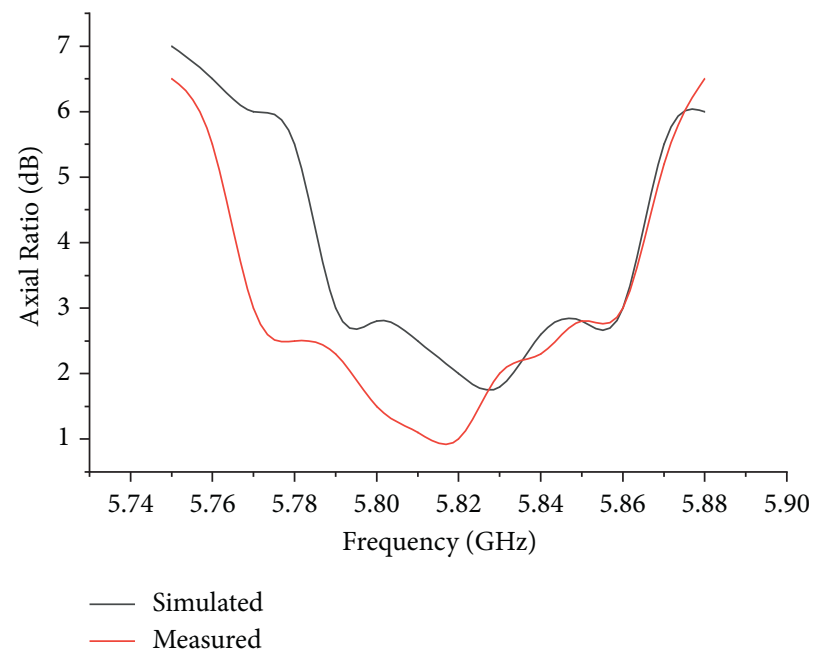

Figure 12: Simulated and measured $3 \mathrm{~dB}$ ARs. 


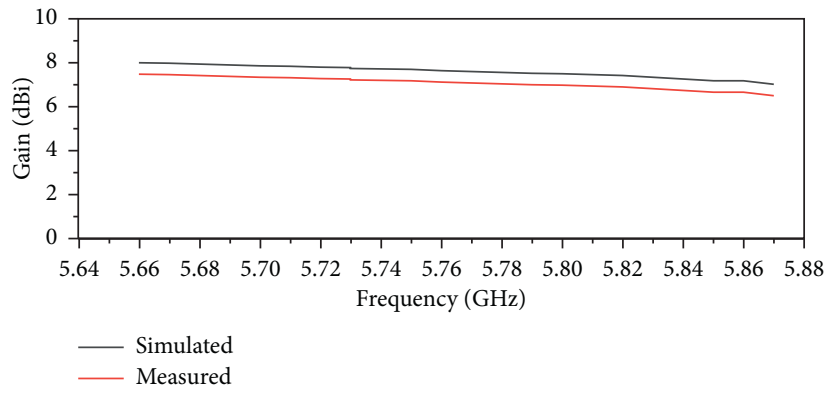

FIGURE 13: Simulated and measured gains.

TABLE 4: Comparison of the proposed antenna array with several $2 \times 2$ SR arrays reported in the literature at $5.8 \mathrm{GHz}$.

\begin{tabular}{lccccc}
\hline References & Peak gain $(\mathrm{dBi})$ & Bandwidth $(\%)$ & Cross polarization $(\mathrm{dB})$ & Efficiency & Size based on wavelength \\
\hline$[23]$ & 10.5 & 17.39 & 25 & Not available & $1.34 \lambda_{0} \times 1.34 \lambda_{0}$ \\
{$[29]$} & 7.46 & 52 & Not available & Not available & $1.868 \lambda_{0} \times 1.868 \lambda_{0}$ \\
{$[30]$} & 7.25 & 28.5 & 15 & Not available & $0.64 \lambda_{0} \times 0.64 \lambda_{0}$ \\
{$[31]$} & 8.25 & 29 & 12 & Not available & $0.86 \lambda_{0} \times 0.86 \lambda_{0}$ \\
Proposed work & 7.48 & 3.85 & 20 & $80-84 \%$ & $0.696 \lambda_{0} \times 0.599 \lambda_{0}$ \\
\hline
\end{tabular}

\section{Conclusion}

In this study, a compact $C P$ quasi-lumped antenna array was introduced. The proposed array was fed by a microstrip using the shorting pins technique to achieve $C P$ radiation. The good agreement between the results from simulation and experiment validated our design. A significant reduction in the size of the array is observed compared to the conventional CP microstrip antennas reported in the literature. Table 4 presents a comparison between several reported $2 \times 2$ $S R$ arrays and the array presented in this study.

\section{Data Availability}

The data used to support the findings of this study are available from the corresponding author upon reasonable request.

\section{Conflicts of Interest}

The author declares no conflicts of interest.

\section{Acknowledgments}

The author would like to thank the Deanship of Scientific Research at Majmaah University for supporting this work, under project no. R-2021-213.

\section{References}

[1] A. Asmeida, Z. Z. Abidin, S. Mohd Shah, M. R. Kamarudin, N. A. Malek, and J. Nebhen, "Wideband crescent-shaped slotted printed antenna with radiant circular polarisation," International Journal of Antennas and Propagation, vol. 2021, Article ID 9975679, 12 pages, 2021.

[2] I. Fatima, A. Ahmad, S. Ali, M. Ali, and M. I. Baig, "Tripleband circular polarized antenna for WLAN/Wi-Fi/Bluetooth/ WiMAX applications," Progress in Electromagnetics Research C, vol. 109, pp. 65-75, 2021.
[3] N. L. Nguyen, "A CPW-fed quasi-PIFA antenna using quasilumped resonators for mobile phones," Progress in Electromagnetics Research M, vol. 87, pp. 127-136, 2019.

[4] G. Kumar and K. P. Ray, Broadband Microstrip Antennas, Artech House, London, UK, 2003.

[5] P. Bhartia, I. Bahl, R. Garg, and A. Ittipiboon, Microstrip Antenna Design Handbook, Artech House, London, UK, 2000.

[6] A. Vahora and K. Pandya, "Implementation of cylindrical dielectric resonator antenna array for wi-fi/wireless LAN/ satellite applications," Progress in Electromagnetics Research M, vol. 90, pp. 159-166, 2020.

[7] J. Maharjan and D. Y. Choi, "Four-element microstrip patch array antenna with corporate-series feed network for $5 \mathrm{G}$ communication," International Journal of Antennas and Propagation, vol. 2020, Article ID 8760297, 12 pages, 2020.

[8] A. Petosa, Dielectric Resonator Antenna Handbook, Artech House, Boston, 2007.

[9] K. F. Tong and T. P. Wong, "Circularly polarized U-slot antenna," IEEE Transactions on Antennas and Propagation, vol. 55, no. 8, pp. 2382-2385, 2007.

[10] M. Biswas and M. Dam, "Closed-form model to determine the Co-axial probe reactance of an equilateral triangular patch antenna," International Journal of Microwave and Wireless Technologies, vol. 10, pp. 801-813, 2018.

[11] T. Z. Dimitrijevic, J. J. Jokovic, and N. S. Donco, "Frequency adjustable dual-band microstrip gap-ring-slot antenna design using the cylindrical TLM method," Applied Computational Electromagnetics Society Journal, vol. 34, no. 5, pp. 631-641, 2019.

[12] J. S. Row, "Design of square-ring microstrip antenna for circular polarization," Electronics Letters, vol. 40, no. 2, pp. 93-95, 2004.

[13] H. Zhang, Y. Q. Li, X. Chen, Y. Qi Fu, and N. C. Yuan, “Design of circular/dual-frequency linear polarization antennas based on the anisotropic complementary split ring resonator," IEEE Transactions on Antennas and Propagation, vol. 57, no. 10, pp. 3352-3355, 2009.

[14] N. Nasimuddin, X. Qing, and Z. Chen, "Compact symmetricslit microstrip antennas for circular polarization," IEEE 
Transactions on Antennas and Propagation, vol. 59, no. 1, pp. 285-288, 2011.

[15] H. D. Chen, S. H. Kuo, C. Y. Desmond Sim, and C. H. Tsai, "Coupling-feed circularly polarized RFID tag antenna mountable on metallic Surface," IEEE Transactions on Antennas and Propagation, vol. 60, no. 6, pp. 2166-2174, 2012.

[16] Z. X. Liang, D. C. Yang, X. C. Wei, and E. P. Li, "Dual-band dual circularly polarized microstrip antenna with two eccentric rings and an arc-shaped conducting strip," IEEE Antennas and Wireless Propagation Letters, vol. 15, pp. 834837, 2015.

[17] M. F. Ain, S. S. Olokede, Y. M. Qasaymeh et al., "A novel 5.8 $\mathrm{GHz}$ quasi-lumped element resonator antenna," International Journal of Electronics and Communications, vol. 67, no. 7, pp. 557-563, 2013.

[18] H. D Schubert, "Microstrip antenna with polarization diversity," U.S. Patent US4410891A, 1983.

[19] B. Xi, Y. Li, and Y. Long, "A miniaturized periodic microstrip leaky wave antenna with shorting pins," International Journal of Antennas and Propagation, vol. 2019, no. 7, 2019.

[20] J. Y. Sze, C. I. G. Hsu, M. H. Ho, Y. H. Ou, and M. T. Wu, "Design of circularly polarized annular-ring slot antennas fed by a double-bent microstrip line," IEEE Transactions on Antennas and Propagation, vol. 55, no. 11, pp. 3134-3139, 2007.

[21] P. S. Hall, J. S. Dahele, and J. R. James, "Design principles of sequentially fed, wide bandwidth, circularly polarised microstrip antennas," IEEE Proceedings $H$ - Microwaves, Antennas and Propagation, vol. 136, no. 5, pp. 381-389, 1989.

[22] T. Teshirogi, M. Tanaka, and W. Chujo, "Wideband circularly polarized array antenna with sequential rotations and phase shifts of elements," in Proceedings of the International Symposium on Antennas Propagation (ISAP'85), pp. 117-120, Tokyo, Japan, Auguest 1985.

[23] S. Maddio, "Parasitic-enhanced circularly polarised sequential antenna array for dedicated short-range communication applications at $5.8 \mathrm{GHz}$," Electronics Letters, vol. 53, no. 13, pp. 824-826, 2017.

[24] M. M. Shirkolaei, "Wideband linear microstrip array antenna with high efficiency and low side lobe level," International Journal of RF and Microwave Computer-Aided Engineering, vol. 30, no. 11, pp. 824-826, 2020.

[25] M. M. Shirkolaei, "High efficiency X-band series-fed microstrip array antenna," Progress in Electromagnetics Research C, vol. 105, pp. 824-826, 2020.

[26] H. G. Akhavan and D. Mirshekar-Syahkal, "Approximate model for microstrip fed slot antennas," Electronics Letters, vol. 30 , no. 23 , pp. $35-45,2020$.

[27] Y. Qasaymeh, K. Issa, A. Al-Ahmadi, and O. Mohamadariff, "A novel herringbone circularly polarized quasi lumped antenna array," Applied Computational Electromagnetics Society Journal, vol. 34, no. 8, pp. 1152-1157, Aug. 2019.

[28] Y. M. Qasaymeh, A. Almuhaisen, and K. Issa, "Design of compact dual circularly polarized concentric ring series-fed quasi-lumped antenna array," Progress in Electromagnetics Research C, vol. 103, pp. 111-121, 2020.

[29] V. Rafii, J. Nourinia, C. Ghobadi, J. Pourahmadazar, and B. S. Virdee, "Broadband circularly polarized slot antenna array using sequentially rotated technique for C-band Applications," IEEE Antennas and Wireless Propagation Letters, vol. 12, pp. 128-131, 2013.

[30] S. Maddio, "A circularly polarized antenna array with a convenient bandwidth/size ratio based on non-identical disc elements," Progress in Electromagnetics Research Letters, vol. 57, pp. 47-54, 2015.

[31] S. Maddio, "A compact wideband circularly polarized antenna array for C-band Applications," IEEE Antennas and Wireless Propagation Letters, vol. 14, pp. 1081-1084, 2015. 